\title{
A genetically engineered human pancreatic $\beta$ cell line exhibiting glucose-inducible insulin secretion
}

\author{
Philippe Ravassard,,1,2,3 Yasmine Hazhouz,2,4 Séverine Pechberty, 4,5 Emilie Bricout-Neveu,2,4 \\ Mathieu Armanet, ${ }^{6,7}$ Paul Czernichow, ${ }^{4}$ and Raphael Scharfmann ${ }^{5}$
}

\begin{abstract}
${ }^{1}$ Université Pierre et Marie Curie-Paris 6, Biotechnology and Biotherapy Team, Centre de Recherche de l'Institut du Cerveau et de la Moelle épinière (CRICM), UMRS 975, Paris, France. ${ }^{2}$ CNRS, UMR 7225, Paris, France. ${ }^{3}$ INSERM, U975, Paris, France. ${ }^{4}$ Endocells, Paris, France. 5 INSERM U845,

Research Center Growth and Signalling, Université Paris Descartes, Sorbonne Paris Cité, Faculté de Médecine, Hôpital Necker, Paris, France. ${ }^{6}$ Cell Therapy Unit, Hôpital Saint Louis, AP-HP, and University Paris 7, Paris, France. 7 Inserm U872, Centre de Recherches des Cordeliers, Paris, France.
\end{abstract}

\begin{abstract}
Despite intense efforts over the past 30 years, human pancreatic $\beta$ cell lines have not been available. Here, we describe a robust technology for producing a functional human $\beta$ cell line using targeted oncogenesis in human fetal tissue. Human fetal pancreatic buds were transduced with a lentiviral vector that expressed SV40LT under the control of the insulin promoter. The transduced buds were then grafted into SCID mice so that they could develop into mature pancreatic tissue. Upon differentiation, the newly formed SV40LT-expressing $\beta$ cells proliferated and formed insulinomas. The resulting $\beta$ cells were then transduced with human telomerase reverse transcriptase (hTERT), grafted into other SCID mice, and finally expanded in vitro to generate cell lines. One of these cell lines, EndoC- $\beta \mathrm{H} 1$, expressed many $\beta$ cell-specific markers without any substantial expression of markers of other pancreatic cell types. The cells secreted insulin when stimulated by glucose or other insulin secretagogues, and cell transplantation reversed chemically induced diabetes in mice. These cells represent a unique tool for large-scale drug discovery and provide a preclinical model for cell replacement therapy in diabetes. This technology could be generalized to generate other human cell lines when the cell type-specific promoter is available.
\end{abstract}

\section{Introduction}

Pancreatic $\beta$ cells are highly specialized endocrine cells that produce, store, and secrete insulin, the only physiological hypoglycemic hormone in the body. Clusters of such cells, which make up about $1 \%$ of the total pancreatic cells, form the islets of Langerhans, the micro-organs that lie scattered throughout the exocrine pancreas. In addition to $\beta$ cells, these micro-organs have other cell types, such as $\alpha, \delta$, and PP cells, which produce glucagon (GCG), somatostatin (SST), and pancreatic polypeptide, respectively. Due to their scattered distribution in the exocrine pancreas, the isolation of a homogeneous population of pancreatic $\beta$ cells remains challenging. Furthermore, the use of growth factors to promote the expansion of adult human $\beta$ cells induced their dedifferentiation in vitro $(1,2)$. Human embryonic stem cells (hESCs) have also been recently tested as an unlimited $\beta$ cell source; however, the procedures for generating functional $\beta$ cells from hESCs have not been fully developed (3). Thus, alternate strategies for the mass production of functional human $\beta$ cells still need to be developed.

During the past 30 years, a number of $\beta$ cell lines have been established from $x$-ray-induced insulinomas in adult rats $(4,5)$ or derived by simian virus 40 transformation of adult hamster islet cells (6). Other rodent $\beta$ cell lines have been generated by targeted oncogenesis in transgenic mice that expressed the SV40LT under the control of the insulin promoter $(7,8)$. These lines have been extremely useful for detailed study of rodent $\beta$ cells (9). Since many differences exist between rodent and human $\beta$ cells, attempts have been made to

Conflict of interest: Philippe Ravassard, Paul Czernichow, and Raphael Scharfmann are shareholders and consultants for Endocells.

Citation for this article: J Clin Invest. 2011;121(9):3589-3597. doi:10.1172/JCI58447. generate human $\beta$ cell lines from many human pancreatic sources, such as adult islets, fetal pancreases, or insulinomas. However, insulin production by these cells was extremely low or these cells were capable of producing insulin only over a few passages (10-13). In 2005, Narushima et al. (14) reported that they successfully established a functional human $\beta$ cell line, NAKT-15. Although this particular human $\beta$ cell line looked promising for cell therapy of diabetes mellitus (DM) and drug screening (15), no new reports on the utility of this line have been published since 2005. Thus, developing a functional human $\beta$ cell line still remains crucial.

Here, we report the establishment of a robust technology for producing a stable functional human $\beta$ cell line with glucoseinducible insulin secretion using targeted oncogenesis in human fetal pancreatic tissue. We transduced human fetal pancreases with a lentiviral vector that expressed SV40LT under the control of the insulin promoter. The transduced pancreases were next grafted into SCID mice so that they could develop into pancreatic tissue. The human $\beta$ cells differentiated, expressed SV40LT concomitantly with insulin, proliferated, and formed insulinomas. The insulinomas were next transduced with a lentiviral vector that expressed human telomerase reverse transcriptase (hTERT), and then the hTERT-transduced insulinomas cells were grafted into other SCID mice in order to further amplify the proliferating $\beta$ cells. After removing the transplanted tissue from these SCID mice, cells were dissociated and then expanded in culture as cell lines. One cell line, EndoC- $\beta \mathrm{H} 1$, was further characterized. EndoC- $\beta \mathrm{H} 1$ cells contained $0.48 \mu \mathrm{g}$ of insulin per million cells, were stable at least for 80 passages, and expressed many specific $\beta$ cell markers, without any substantial expression of markers of other pancreatic cell types. EndoC- $\beta \mathrm{H} 1$ cells secrete 

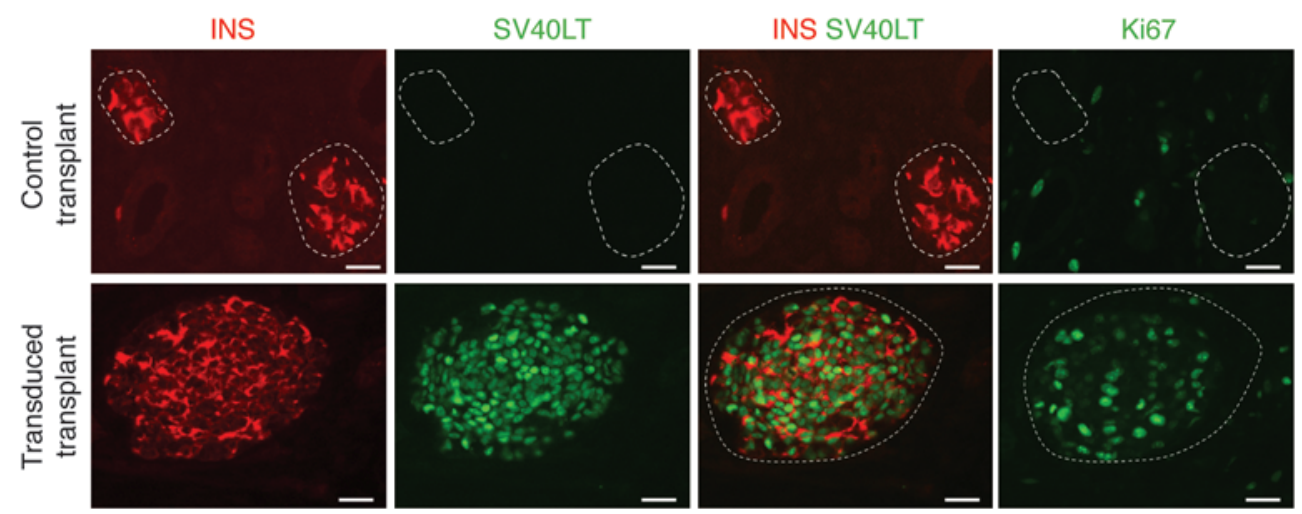

\section{Figure 1}

In vivo expansion of SV40LT-expressing cells in transplanted human fetal pancreas. Human fetal pancreases that were transduced or not transduced with an SV40LT-expressing lentiviral vector were transplanted under the kidney capsule of SCID mice. 3 months later, insulin (INS) immunostaining (red) revealed $\beta$ cell clusters in both the nontransduced and SV40LT-transduced fetal pancreases. In the nontransduced pancreases, the $\beta$ cells stained negative for both SV4OLT (green) and Ki67 (green), whereas $\beta$ cell clusters coexpressed SV40LT and INS in the SV40LT-transduced transplants. Such clusters proliferated, as visualized by Ki67 staining. Scale bars: $50 \mu \mathrm{m}$.

insulin in response to glucose stimulation, and insulin secretion is enhanced by known secretagogues, such as exendin-4, glibenclamide, and leucine. Finally, transplantation of EndoC- $\beta \mathrm{H} 1$ cells into mice reversed chemically induced DM.

By developing an innovative method of targeted oncogenesis in human fetal pancreas, we have successfully generated a robust functional human $\beta$ cell line that has glucose-inducible insulin secretion. This cell line has the potential to be a unique tool of major importance for intensive studies of the human $\beta$ cell and drug screening as well as being a useful preclinical model for testing replacement cell therapy in DM.

\section{Results}

Expansion of insulin-positive cells derived from buman fetal pancreas. Human fetal pancreatic rudiments were first transduced with a lentiviral vector that expressed SV40LT under the control of a 405-nt fragment of the rat insulin II promoter. The resultant transduced tissues were next transplanted under the kidney capsules of SCID mice. As previously shown, within a few months after transplantation, complete pancreatic differentiation with morphogenesis of functional islets of Langerhans occurred $(16,17)$. We also showed that integrative lentiviral transduction resulted in the generation of a transgenic-like human pancreas where transgene expression is dependent on the cell type-specific promoter that drives the transgene (18). Therefore, we asked whether such an approach using SV40LT under the control of a rat insulin promoter could be used to promote human $\beta$ cell proliferation. Three months after pancreatic transplantation, nontransduced fetal pancreases developed $\beta$ cell clusters that contained insulin-positive cells that were rarely positive for the proliferation marker Ki67 (Figure 1). In the SV40LT-transduced human fetal pancreases, the transgene was detected in the insulin-positive cells, a finding that confirms the $\beta$ cell specificity of the rat insulin promoter. SVL40LT-expressing cells were located in a subset of $\beta$ cell clusters and importantly, such $\beta$ cells were the ones that stained positive for Ki67 (Figure 1). Collectively, such data demonstrate that SV40LT expression in human fetal pancreatic $\beta$ cells triggers their proliferation.

We next asked whether the proliferation of these $\beta$ cells could give rise to primary insulinomas. From 6 to 8 months after transplanting SV40LT-transduced human fetal pancreases into SCID mice, the mice became hypoglycemic. Analysis of the transplants revealed highly vascularized areas (Figure 2A) that were enriched in insulin-positive cells that stained positive for SV40LT and Ki67 (Figure 2, B-D). We next determined whether similar results could be obtained using adult human islets that were transduced with SV40LT. Transduction of adult human islets with the lentiviral vector was efficient (Supplemental Figure 1; supplemental material available online with this article; doi:10.1172/JCI58447DS1), but insulinomas never developed after their transplantation into SCID mice (Figure 2E). Specifically, such cells rarely proliferated, although insulin-positive cells were clearly present 6 months after transplantation (Figure 2, $\mathrm{F}-\mathrm{H})$. Moreover, these SCID mice were not hypoglycemic, even after 10 months. Thus, SV40LT transduction was inefficient in driving the expansion of adult $\beta$ cells, whereas it actively promoted the proliferation of insulin-positive cells that differentiated from the transduced human fetal pancreas.

Insulinoma formation from human fetal pancreases was reproducibly achieved in more than 50 different experiments using the above-described procedure. The primary insulinomas that developed after transplantation of the SV40LT-transduced fetal pancreases (Figure 2) were removed from the mice. The highly vascularized tissue of the tumors was dissociated into small cell clusters, which were retransduced with a lentiviral vector that expressed hTERT in order to prevent their senescence. The clusters were then transplanted into other SCID mice for $\beta$ cell enrichment. This second transplantation of SV40LT- and hTERT-transduced cells reproducibly caused hypoglycemia in the mice and yielded an almost homogenous tissue in which all the actively proliferating cells expressed insulin, SV40LT, and PDX1 (Figure 3, A-C). Importantly, none of the cells were positive for the $\alpha$ cell marker GCG (Figure 3D) or the acinar cell marker amylase (Figure 3E).

EndoC- $\beta$ H1 buman $\beta$ cell line derivation and characterization. Using serial transplantation of transduced fetal pancreases, we were able to cause the reproducible development of secondary human insulinomas in more than 500 mice. This was instrumental for defining the most appropriate culture conditions for the in vitro expansion of pancreatic $\beta$ cells and cell line derivation. We found 

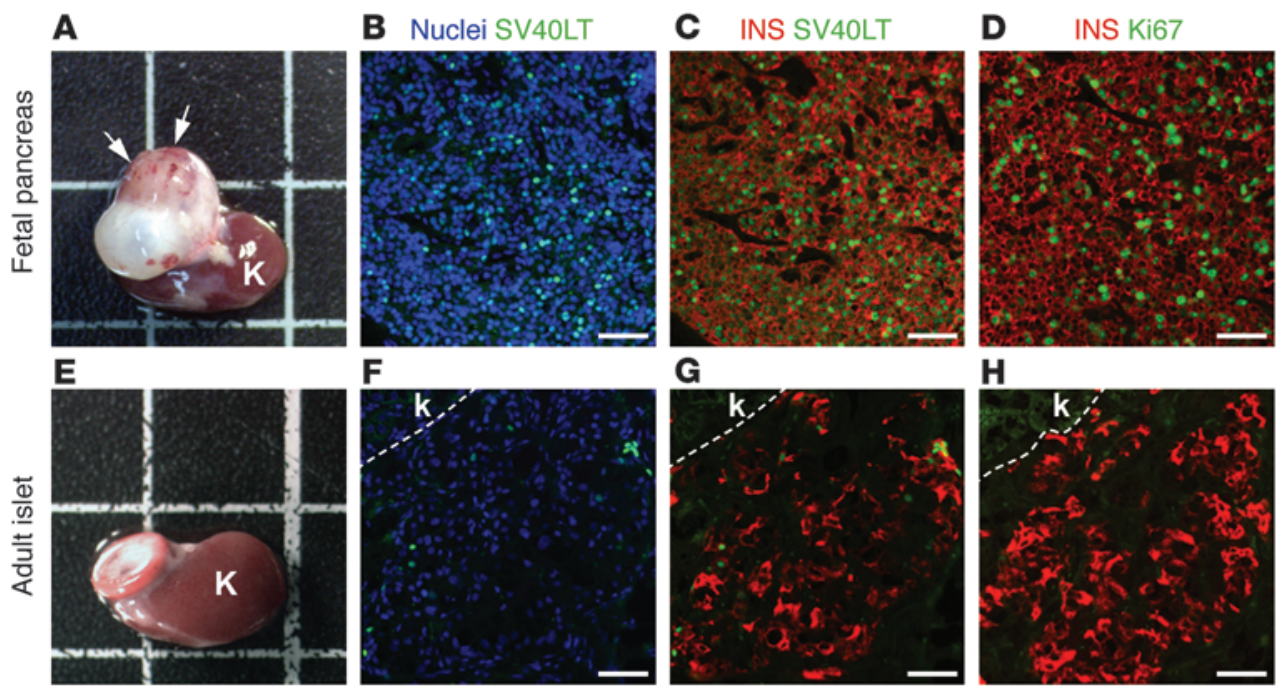

$\mathbf{F}$

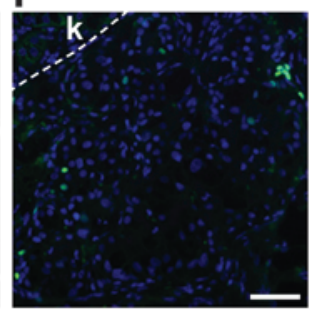

G

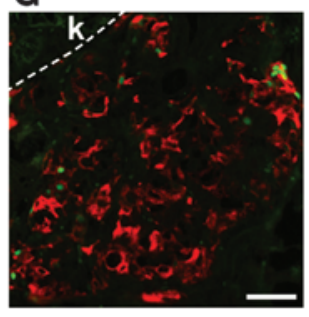

$\mathbf{H}$

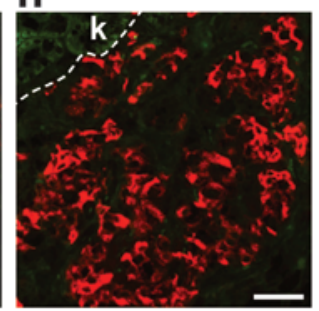

Figure 2

Primary insulinomas develop from SV40LT-transduced fetal pancreases, but not from adult islets. Human fetal pancreases and adult islets were transduced with an SV4OLT-expressing lentiviral vector, transplanted under kidney (K) capsule, and then removed 6 to 8 months later. (A-D) In the transduced human fetal pancreatic grafts, substantial tissue expansion and highly vascularized regions were observed (arrows). Histological examination of sections of this vascularized domain revealed a large population of cells that stained positively for both SV4OLT (green) and insulin (red) and expressed Ki67 (green). (E-H) In transduced human adult islet grafts, insulin-positive cells (red) were abundant, and SV40LTpositive cells (green) were rarely observed. However, their proliferation remained low, as measured by Ki67 (green), and no tissue expansion was observed. (A and E) Square size in grids: $1 \mathrm{~cm}$. Scale bars: $50 \mu \mathrm{m}$.

that their culture on Matrigel/fibronectin-coated plates with $5.6 \mathrm{mM}$ glucose in the absence of serum, but with BSA, was permissive for cell line derivation.

Here, we describe 1 cell line named EndoC- $\beta$ H1 (Figure 4A). This line could be frozen, thawed, and amplified with a doubling time of 5 days without any significant morphological changes until at least passage 80 . We first used real-time PCR to characterize the transcripts that were expressed in EndoC- $\beta \mathrm{H} 1$ cells. Comparisons were performed with cDNAs that were prepared from an adult human islet cell preparation that contained $40 \%$ $\beta$ cells (Supplemental Figure 2 ). Expression of the $\beta$ cell transcription factors PDX1, MAFA, NKX6-1, PAX6, and NEUROD1 was detected in the EndoC- $\beta \mathrm{H} 1$ cells at levels that were similar to those in human islet cell preparation. RNA that coded for insulin was detected at marked levels (40\% of that found in the islet cell preparation), while mRNAs that coded for islet amyloid pancreatic polypeptide (IAPP), GCG, and SST (SST) were barely detectable (Figure $4 \mathrm{~B}$ ). EndoC- $\beta \mathrm{H} 1$ cells expressed high levels of mRNA that coded for glucokinase (GCK), a hexokinase that is a glucose sensor in pancreatic $\beta$ cells (Figure 4B). Additional $\beta$ cell markers were expressed in the EndoC- $\beta \mathrm{H} 1$ cells at $20 \%-60 \%$ of the expression level that was measured in islet preparation. This is the case for (a) the glucose transporter SLC2A2, (b) the insulinprocessing enzyme PCSK1, (c) the KCNJ11 and ABCC8 subunits of the ATP-sensitive potassium channel, which are targets of the sulfonylurea drugs, and (d) genes that are associated with the $\beta$ cell secretory machinery, such as the vesicular $\beta$ cell zinc transporter, SLC30A8, the $25-\mathrm{kDa}$ synaptosomal-associated protein, SNAP25, and the small G protein, RAB3A. Finally, EndoC- $\beta \mathrm{H} 1$ cells express GAD2 and PTPRN, which encode GAD65, the $65-\mathrm{kDa}$ isoform of glutamic acid decarboxylase enzyme and the transmembrane protein tyrosine phosphatase receptor type $\mathrm{N}$, against both of which autoantibodies develop in DM. Importantly, no significant levels of carboxypeptidase A (CPA1) and CFTR, which are acinar and duct cell markers, respectively, were detected in the EndoC- $\beta \mathrm{H} 1$ cells.

All cells were positive for insulin, C-peptide, PDX1, NKX6-1, and the pan-endocrine marker, chromogranin A. The cells also expressed SV40LT and were capable of proliferation, as measured by Ki67 staining (Figure 5). Importantly, EndoC- $\beta \mathrm{H} 1$ cells were negative for GCG, and less than $0.05 \%$ of the cells in culture expressed SST (Supplemental Figure 3). Finally, EndoC- $\beta \mathrm{H} 1$ cells stained negative for amylase and Sox9, which are acinar and ductal cell markers, respectively.

Insulin contentand secretion. EndoC- $\beta \mathrm{H} 1$ cells contained $0.46 \pm 0.07 \mu \mathrm{g}$ insulin per million cells (the mean \pm SEM of 19 independent determinations that were made between passages 25 and 75). Insulin content was stable with passages. EndoC- $\beta \mathrm{H} 1$ cells contained a mean of $0.46 \pm 0.08 \mu \mathrm{g} / 10^{6}$ cells from passages 25 to $40,0.53 \pm$ $0.08 \mu \mathrm{g} / 10^{6}$ cells from passages 40 to 60 , and $0.45 \pm 0.05 \mu \mathrm{g} / 10^{6}$ cells from passages 60 to 75 . Glucose-stimulated insulin secretion by EndoC- $\beta \mathrm{H} 1$ cells increased 3-fold in a dose-dependent manner over the $0.5-20 \mathrm{mM}$ glucose concentration range (Figure $6 \mathrm{~A}$ ). Specifically, EndoC- $\beta \mathrm{H} 1$ cells secreted $5.96 \pm 0.52 \mathrm{ng} / \mathrm{h} / 10^{6}$ cells at $0.5 \mathrm{mM}$ glucose and $19.29 \pm 1.38 \mathrm{ng} / \mathrm{h} / 10^{6}$ cells at $20 \mathrm{mM}$ glucose. Glucose stimulation of insulin secretion was stable with passages. Mean stimulation index between 2.8 and $15 \mathrm{mM}$ glucose was $2.63 \pm 0.17$ from passages 25 to $40,2.54 \pm 0.47$ from passages 40 to 60 , and $2.24 \pm 0.13$ from passages 60 to 75 . The GCG-like peptide 1 receptor (GLP1R) agonist, exendin-4, also stimulated insulin secretion (Figure 6B). Glibenclamide, a sulfonylurea that blocks the KCNJ11/ABCC8 ATP-sensitive potassium channel, caused a 2.6-fold increase in insulin secretion when compared with that caused by $11 \mathrm{mM}$ glucose, while the potassium chan- 

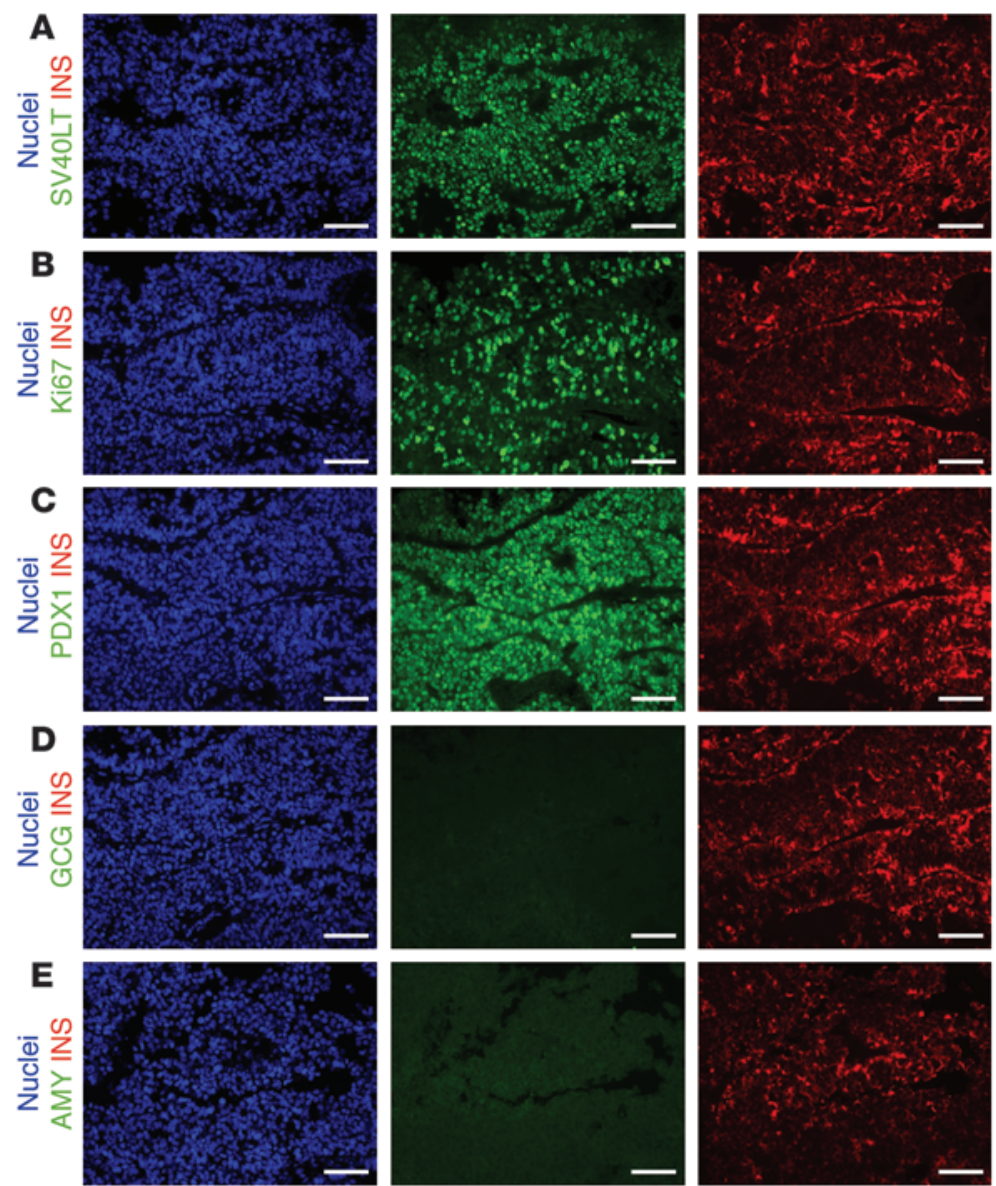

Figure 3

Secondary insulinomas are homogeneously composed of proliferating insulinpositive cells. Primary insulinomas were transduced with a lentiviral vector that expressed hTERT and then transplanted into SCID mice. 2 months later, secondary insulinomas were analyzed by immunostaining. (A-E) The entire tissue stained positive for insulin (INS) (red). All nuclei (blue) were positive for SV40LT (A, green) and PDX1 (C, green). A large number of cells proliferated, as indicated by Ki67positive staining (B, green). No expression of glucagon (D) or amylase (E) was detected. Scale bars: $50 \mu \mathrm{m}$.

nel opener diazoxide inhibited insulin secretion (Figure 6B). Insulin secretion was responsive to an increase in cAMP, as demonstrated using the phosphodiesterase inhibitor IBMX. The branched amino acid L-leucine caused a 4-fold increase in insulin secretion over the basal level (Figure 6B). Finally, the basal levels of insulin secretion returned when EndoC- $\beta \mathrm{H} 1$ cells were cultured at $2.8 \mathrm{mM}$ D-glucose following their stimulation with $11 \mathrm{mM}$ D-glucose in the presence or absence of IBMX (Figure 6C).

EndoC- $\beta H 1$ cell transplantation reverts chemically induced DM in $S C I D$ mice. In order to evaluate the in vivo function of EndoC- $\beta \mathrm{H} 1$ cells, DM was chemically induced in SCID mice by streptozotocin (STZ) injection. All the mice were hyperglycemic 2 days after the STZ injection. Six of these mice were randomly selected for an EndoC- $\beta \mathrm{H} 1$ cell transplant $\left(2 \times 10^{6}\right.$ cells $)$. Within a few days, the blood glucose levels of these mice dramatically fell to levels that were lower than those of the nontransplanted DM animals (Figure 7A). Glucose tolerance test established that the transplanted cells respond to a rapid rise in blood glucose levels
(Figure 7B). When the transplanted cells were removed by unilateral nephrectomy, the mice became hyperglycemic, and this finding confirms that the blood glucose levels of the STZ-treated mice were controlled by the transplanted cells. Histological analysis of the cell graft revealed the presence of a large mass of proliferating human insulin-positive cells (Figure 7C), and the pancreases of the STZ-induced DM mice were almost entirely devoid of $\beta$ cells (Figure 7D). Of note, when the duration of transplanted cells was longer than 35 days, the cell-transplanted STZ-treated SCID mice became hypoglycemic due to constitutive expansion of the transplanted cells.

\section{Discussion}

Here, we describe the generation of a functional human pancreatic $\beta$ cell line. Availability of human primary $\beta$ cells is limited, and their purification from human pancreatic islet preparations is challenging (19). In rodents, $\beta$ cell lines have been available since the beginning of the 1970s and were extremely useful in studying $\beta$ cell function (9). However, rodent $\beta$ cells are not ideal for studying human $\beta$ cells because human and rodent $\beta$ cells differ from one another in many ways. For example, insulin is encoded by 2 genes in rodents and by only 1 gene in humans (20). Functional differences between rodent and human $\beta$ cells are suggested by the difference in the relative role of glucose transport and phosphorylation in glucose sensing (21). Interestingly, based on data obtained with rodent $\beta$ cells, the glucose transporter SLC2A2 was first proposed to be a glucose sensor protein (22). However more recent studies reported an extremely low level of SLC2A2 expression in human islet cells $(23,24)$, suggesting that while glucose is transported by SLC2A2 in rat $\beta$ cells, it is mainly transported by SLC2A1 and/or SLC2A3 in human $\beta$ cells (21). In the present work, we found that SLC2A2 mRNA was expressed in EndoC- $\beta \mathrm{H} 1$ cells. Thus, EndoC- $\beta \mathrm{H} 1$ cells should represent a useful model for dissecting the specific role of the different glucose transporters in human $\beta$ cells. The sensitivity to cytotoxic drugs, such as STZ and alloxan, or cytokines, such as IL-1 $\beta$, also differs between rodent and human $\beta$ cells $(25,26)$. Finally, rodent and human $\beta$ cells express different sets of cyclin-dependent kinases and differ in their proliferative rate (27). In view of these differences between rodent and human $\beta$ cells, our current knowledge of the human $\beta$ cell is incomplete. Since the missing knowledge cannot be obtained from studying rodent $\beta$ cells, transformed human $\beta$ cell lines should be crucial for this purpose.

Previous attempts to generate human $\beta$ cell lines from adult human $\beta$ cells have not always been successful (10-13), with one exception, the NAKT15 cells (14), and these cells were generated by gene transfer using Moloney-based retroviral vectors. However, these vectors can only transduce proliferating cells (28), and the proliferative potential of human adult $\beta$ cells is extremely low (29). Thus, the use of Moloney-based retroviral vectors by Narushima et al. for cell transduction cannot be easily explained, unless they transduced a very rare subpopulation of proliferating cells that were present in their islet prepara- 
A

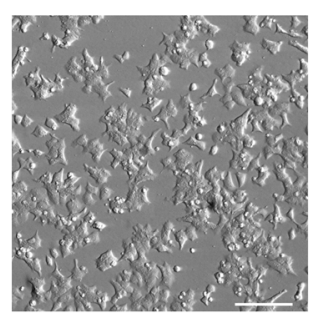

B

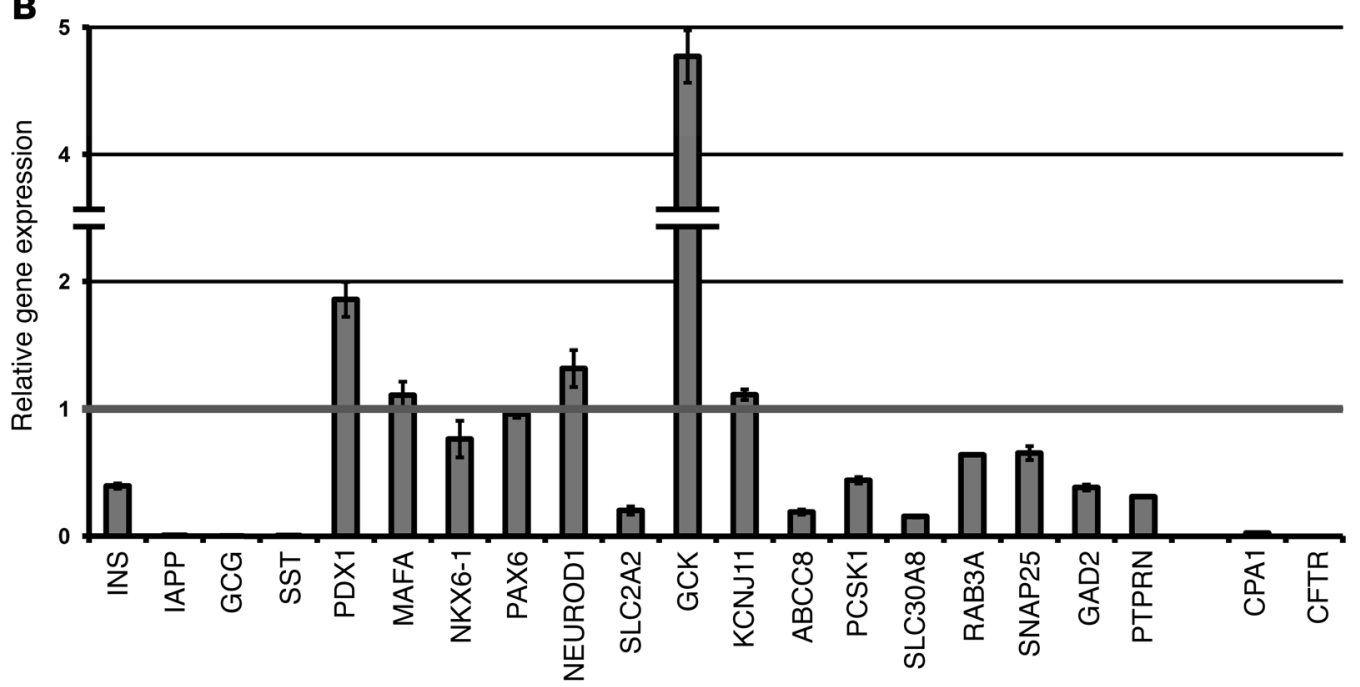

Figure 4

Morphology and gene expression profiling of EndoC- $\beta \mathrm{H} 1$ cells. (A) Morphology of EndoC- $\beta \mathrm{H} 1$ cells at passage 63 . Scale bar: $250 \mu \mathrm{m}$ (B) Quantitative real-time PCR analyses of the indicated genes were performed using cDNA prepared from 3 independent cultures of EndoC- $\beta \mathrm{H} 1$ cells and from 1 adult human islet preparation. Results are presented as mean \pm SEM of the levels that were measured in human islets.

tions (14). Since the publication of the method for generating the NAKT15 $\beta$ cell line, we are not aware of any other reports on its utility. Here, we attempted to generate a functional human $\beta$ cell line from adult human islets after their transduction by lentiviral vectors. The transduced cells survived after their transplantation into immunoincompetent mice, but the transplanted cells did not develop into insulinomas. These observations are consistent with those in a recent communication reporting that adult $\beta$ cells are refractory to transformation using multiple oncogenic mutants (30).

In the present study, we succeeded in producing $\beta$ cell lines from human fetal pancreases. In the past, many attempts to generate human $\beta$ cells were done using 18- to 25 -week-old human fetal pancreases that were transduced with oncogenes. Such an approach did not give rise to functional and stable human $\beta$ cell lines $(31,32)$. Here, we used lentiviral-mediated gene transfer to generate functional $\beta$ cells from human fetal pancreases, which were at an earlier stage of their development, namely between 9 and 11 weeks, which is the period that coincides with the onset of $\beta$ cell differentiation (33). The integrated transgene SV40LT was under the control of the rat insulin promoter and permitted its specific expression in the insulin-positive cells. By using this targeted approach, SV40LT was expressed in newly formed $\beta$ cells at the same time as insulin was first produced by these cells. Thus, we successfully mimicked the transgenic approach that is used to generate functional rodent $\beta$ cell lines $(7,8,34)$ for developing a functional human $\beta$ cell line from human fetal pancreases.

We developed a multistep procedure for generating human $\beta$ cell lines. First, each transduced human fetal pancreatic bud was transplanted under the kidney capsule of 2 or 3 SCID mice, as this site is a permissive site for human pancreatic development (17). Within 6 to 8 months, all transplanted mice developed primary insulinomas, which caused them to have decreasing blood glucose levels. The primary insulinomas were highly vascularized in comparison with the rest of the pancreatic transplant. These highly vascularized areas in the primary insulinomas were then dissociated, transduced with lentiviruses that expressed hTERT under the control of the rat insulin promoter, and transplanted into other SCID mice. These mice became hypoglycemic within 2 to 3 months, with massive amplification of the insulin-positive cells. Such amplification in vivo was instrumental for maintaining a large collection of proliferating insulin cells and allowed the definition of permissive culture conditions in which an immortalized cell line could be established in vitro.

Each step of the procedure was highly reproducible. Specifically, we produced more than 50 primary insulinomas after transplanting transduced human fetal pancreatic buds into SCID mice. When dissociated cells of these primary insulinomas were transplanted into other SCID mice, these cells could give rise to more than 500 secondary insulinomas. After defining the proper culture condition, $25 \%$ of the secondary insulinomas gave rise to a cell line. We focused our attention on 1 specific line that has high insulin content, the EndoC- $\beta \mathrm{H} 1$ cell. At the RNA level, EndoC- $\beta \mathrm{H} 1$ cells express many $\beta$ cell-specific genes, such as transcription factors, enzymes, and proteins of the secretory machinery at levels that are similar to those found in human $\beta$ cells. One exception was IAPP, a protein that is coexpressed and cosecreted with insulin. The exact physiological function of IAPP has not yet been elucidated, but its aggregation promotes $\beta$ cell apoptosis (35). Amyloid deposition occurs in transplanted human pancreatic islets into mice (36) or into the liver of a DM patient (37). We observed low IAPP expression in EndoC- $\beta \mathrm{H} 1$ cells, and this finding suggests that IAPP-derived amyloid deposition will probably not occur after EndoC- $\beta \mathrm{H} 1$ cell transplantation.

Importantly, the expression levels of markers of other pancreatic cell types were not significant in EndoC- $\beta \mathrm{H} 1$ cells, namely, the respective markers for $\alpha$ and $\delta$ cells, GCG and SST, the ductal markers CFTR and SOX9, and the acinar cell marker amylase. The insulin mRNA content of EndoC- $\beta \mathrm{H} 1$ cells is $40 \%$ of that found in human pancreatic islets, and the insulin 

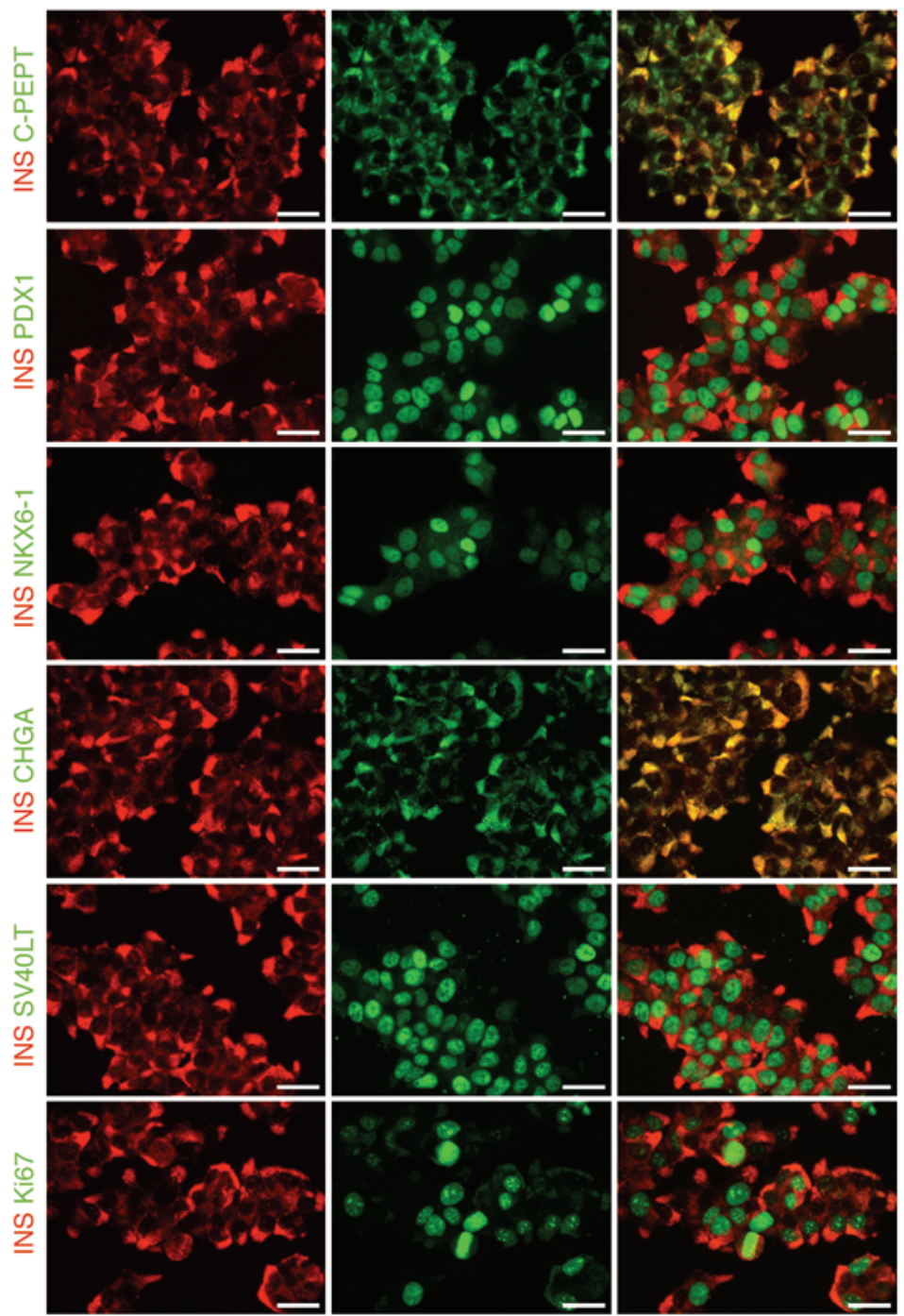

Figure 5

Immunofluorescence analysis of EndoC- $\beta \mathrm{H} 1$ cells. EndoC- $\beta \mathrm{H} 1$ cells stained positive for insulin and coexpressed C-peptide, PDX1, NKX6-1, CHGA, SV40LT, and Ki67. Scale bars: $25 \mu \mathrm{m}$.

content of EndoC- $\beta \mathrm{H} 1$ cells is $0.46 \pm 0.07 \mu \mathrm{g} / 10^{6}$ cells, which is one order of magnitude below that found in human $\beta$ cells (38). Insulin secretion by these EndoC- $\beta \mathrm{H} 1$ cells depends upon the extracellular glucose concentration and has a stimulation index in the same range as that described for primary adult human pancreatic islets (39). Furthermore, the percentage of intracellular insulin content secreted per hour is similar to values that have been reported for human pancreatic islets (40). Our data demonstrate that insulin secretion by these EndoC- $\beta \mathrm{H} 1$ cells can also be influenced by many secretagogues, such as leucine, sulfonylurea drugs, IBMX, and exendin-4, and this finding indicates that EndoC- $\beta \mathrm{H} 1$ cells should be useful for the high throughput screening of new molecules that could be used for controlling insulin secretion. Finally, when transplanted in chemically induced DM SCID mice, EndoC- $\beta \mathrm{H} 1$ cells returned the elevated blood glucose level to normal values, and this finding suggests that EndoC- $\beta \mathrm{H} 1$ cells can also be used for in vivo drug screening in reconstituted animal models. In this context and based on our robust technology, a second generation of human $\beta$ cell lines can now be developed using reverse immortalization.

To conclude, we have developed a robust innovative strategy for generating a stable and functional human pancreatic $\beta$ cell line with glucose-inducible insulin secretion. Such a strategy could be exploited to produce other human cell lines, as long as a specific promoter is available. EndoC- $\beta \mathrm{H} 1$ cells could now be used to better understand human $\beta$ cell physiology and in large-scale drug discovery in addition to as a preclinical model for developing cell replacement therapy in DM.

\section{Methods}

DNA constructs and lentiviral vector productions. The lentiviral construct PTRIP $\Delta$ U3.RIP405-SV40LT has been previously described (34). The lentiviral vector PTRIP $\Delta$ U3.RIP405-eGFP expresses eGFP under the control of the rat insulin II gene promoter (RIP) (41). A new lentiviral vector, pTRIP $\Delta$ U3.RIP405hTERT, was constructed. The RIP405 cassette was first inserted into a pTRIP $\Delta \mathrm{U} 3$ polylinker using the MluI and BamHI restriction endonucleases, and the hTERT XbaI cassette (Geron) was then inserted in pTRIP $\Delta$ U3.RIP405 polylinker. The correct orientation of the integrated hTERT cassette was verified by sequencing. Lentiviral vector stocks were produced by transient transfection of $293 \mathrm{~T}$ cells by encapsidation of the p8.9 plasmid $(\Delta V \operatorname{pr} \Delta$ Vif $\Delta V$ pu $\Delta$ Nef) (42) pHCMV-G, which encoded the VSV glycoprotein $\mathrm{G}(42)$, and the pTRIP $\Delta \mathrm{U} 3$ recombinant vector, as previously described (42). The supernatants were treated with DNAse I (Roche Diagnostic) prior to their ultracentrifugation, and the resultant pellets were resuspended in PBS, aliquoted, and then frozen at $-80^{\circ} \mathrm{C}$ until use. The amount of p24 capsid protein was quantified by the HIV-1 p 24 antigen ELISA (Beckman Coulter). All transductions were normalized relative to p24 capsid protein quantification.

Human tissues and gene transfer. Human fetal pancreases were extracted from tissue fragments that were obtained immediately after elective termination of pregnancy between 7 and 11 weeks gestation, in compliance with French bioethics legislation. Approval was obtained from the Agence de Biomedecine, the French competent authority, along with maternal written consent. Gestational ages were determined from the last menstrual period, the crown-rump length as measured by ultrasonography, and the hand and foot morphology.

Human pancreases were harvested from adult brain-dead organ donors before cardiac death with prior consent for research use. Islets were isolated after enzymatic ductal perfusion by the Ricordi method (43). The isolated islets were then washed and finally cultured in nonadherent culture flasks (Life Technologies Inc.) in CMRL 1066 medium (Sigma-Aldrich) that contained $5.6 \mathrm{mM}$ glucose, $25 \mathrm{mM}$ HEPES, $2 \mathrm{mM}$ glutamine, $100 \mathrm{U} / \mathrm{ml}$ penicillin, $100 \mathrm{mg} / \mathrm{ml}$ streptomycin, and $10 \%$ fetal calf serum at a density of 20,000 islet equivalents in $30 \mathrm{ml}$ before their use in experiments.

Human fetal pancreases and islets were transduced with pTRIP $\Delta U 3$. RIP405-SV40LT, and the primary insulinomas were transduced with PTRIP $\triangle$ U3.RIP405-hTERT, as previously described $(18,41)$. Briefly, tissues were transduced with a total amount of lentiviral vectors corresponding to $2 \mu \mathrm{g}$ of 24 capside protein for 2 hours at $37^{\circ} \mathrm{C}$ in $200 \mu$ l of RPMI 1640 medium supplemented with $10 \%$ heat-inactivated fetal calf serum, HEPES $(10 \mathrm{mM})$, L-glutamine $(2 \mathrm{mM})$, nonessential amino acids (Invitrogen), penicillin- 
A

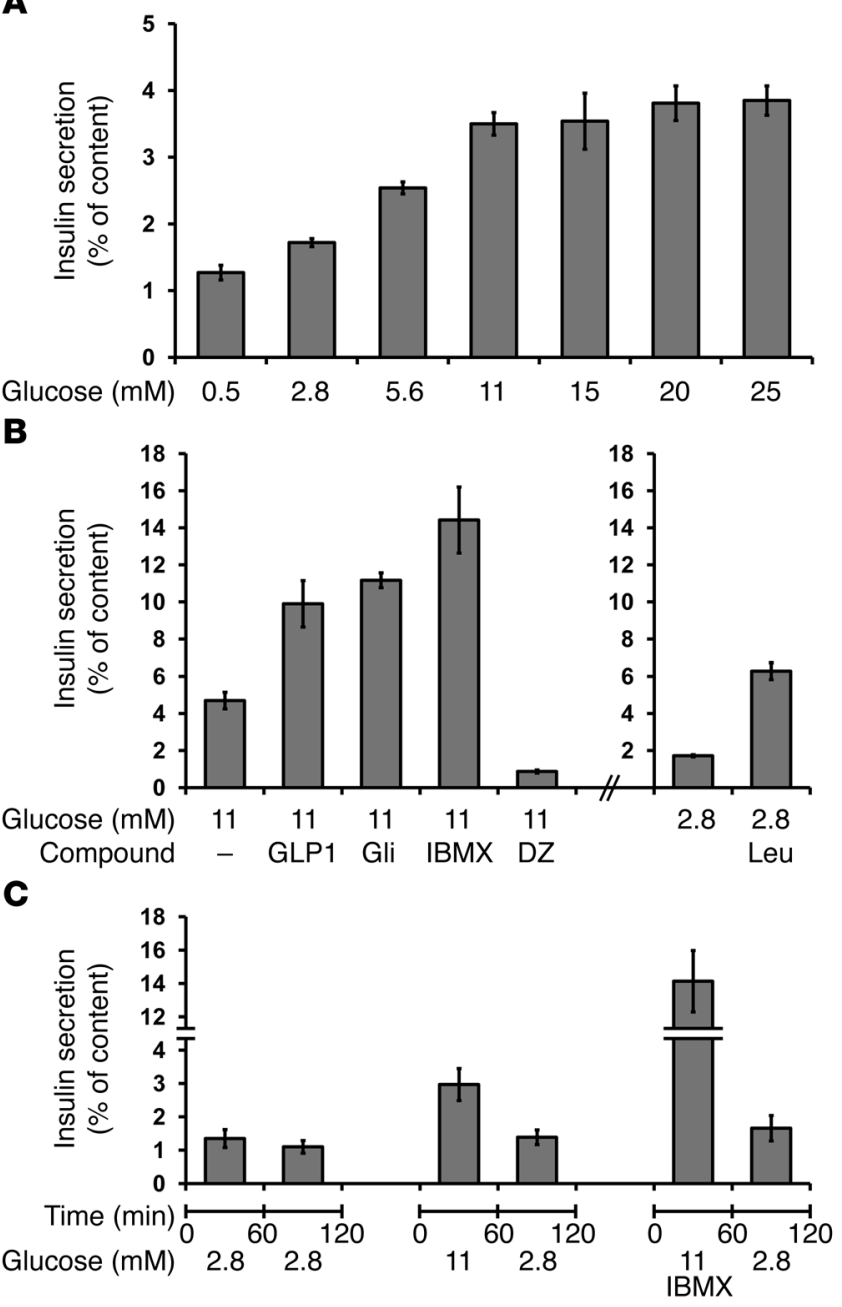

\section{Figure 6}

EndoC- $\beta \mathrm{H} 1$ cells secrete insulin in vitro. (A) EndoC- $\beta \mathrm{H} 1$ cells secreted insulin in response to glucose stimulation. (B) Insulin secretion by EndoC- $\beta \mathrm{H} 1$ cells increased when stimulated with $100 \mathrm{nM}$ exendin- 4 (EX4), $100 \mu \mathrm{M}$ glibenclamide (Gli), $500 \mu \mathrm{M}$ IBMX, and $10 \mathrm{mM}$ L-leucine (Leu). Diazoxine (DZ) treatment $(500 \mu \mathrm{M})$ reduced insulin secretion to basal levels. (C) Insulin secretion was first stimulated for 60 minutes with $11 \mathrm{mM}$ glucose in the presence or absence of IBMX. This medium was the replaced with HEPES-buffered Krebs-Ringer Buffer that contained $2.8 \mathrm{mM}$ glucose, and the cells were further incubated in this medium for 60 minutes. Note that insulin secretion returned to basal level in the presence of $2.8 \mathrm{mM}$ glucose. The figure shows data from a representative experiment that was done in duplicate on 3 experimental replicates. Results are expressed as the mean percentage \pm SEM of the insulin content that was secreted in 1 hour.

derive human $\beta$ cell lines. Culture medium containing or not containing fetal calf serum was tested in the presence of various glucose concentrations. We were unable to derive human cell lines in the presence of fetal calf serum. Thus, cell lines were derived on Matrigel-fibronectin-coated $(100 \mu \mathrm{g} / \mathrm{ml}$ and $2 \mu \mathrm{g} / \mathrm{ml}$, respectively) (Sigma-Aldrich) culture wells in DMEM that contained $5.6 \mathrm{mM}$ glucose, $2 \%$ BSA fraction V (Roche Diagnostics), $50 \mu \mathrm{M}$ 2-mercaptoethanol, $10 \mathrm{mM}$ nicotinamide (Calbiochem), $5.5 \mu \mathrm{g} / \mathrm{ml}$ transferrin (Sigma-Aldrich), $6.7 \mathrm{ng} / \mathrm{ml}$ selenite (Sigma-Aldrich), $100 \mathrm{U} / \mathrm{ml}$ penicillin, and $100 \mu \mathrm{g} / \mathrm{ml}$ streptomycin. Passages were performed when confluence was observed. From passage 14 onwards, a 2/3 dilution passage was performed every week.

Immunostaining of pancreatic explants and cell lines. Tissues were fixed in $3.7 \%$ formaldehyde prior to their embedding in paraffin. For immunohistochemistry, sections (4- $\mu \mathrm{m}$ thick) were prepared and processed, as described previously (44). For immunocytochemistry, EndoC- $\beta \mathrm{H} 1$ cells were cultured on $12-\mathrm{mm}$ glass cover slips that were coated with Matrigel and fibronectin. After 5 days, the cells were then fixed for 1 hour in $4 \%$ paraformaldehyde. The following antibodies were used for immunostaining: guinea pig anti-insulin antibody (1/500; DakoCytomation); rat anti-human C-peptide (1/3,000; Beta Cell Biology Consortium); mouse anti-GCG (1/2,000; Sigma-Aldrich); rabbit anti-SST antibody (1/500; DakoCytomation); mouse anti-chromogranin A (1/50; DakoCytomation); rabbit anti-human PDX1 antibody $(1 / 2,000)(45)$, rabbit antiNKX6-1 antibody (1/500; Beta Cell Biology Consortium); rabbit antiSOX9 antibody (1/500; Millipore); rabbit anti-amylase antibody (1/300; Sigma-Aldrich); mouse anti-SV40LT antibody (1/50; Calbiochem Merck Biosciences); and mouse anti-human Ki67 antigen (1/50; DakoCytomation). The secondary antibodies were fluorescein anti-rabbit antibody (1/200; Jackson Immunoresearch Laboratories, Beckman Coulter); fluorescein anti-mouse antibody (1/200; Immunotech); Alexa Fluor 488 goat anti-rat antibody (1/500; Invitrogen); Texas red anti-guinea pig antibody (1/200; Jackson Immunoresearch Laboratories), and peroxidase antimouse antibody (1/200; Ozyme).

Digital images of the pancreatic explants and cell lines were captured using a cooled 3-chip charge coupled device camera (Hamamatsu C5810; Hamamatsu) that was attached to a fluorescent microscope (Leica; Leitz). $R N A$ isolation, reverse transcription, and real-time-PCR. Total RNA was isolated from EndoC- $\beta \mathrm{H} 1$ cells and adult human islets using the QIAGEN RNeasy Mini Kit (QIAGEN ), as described previously (46). First-strand cDNA was prepared using Superscript Reagents (Invitrogen), and quantitative real-time PCR was done using Assays-on-Demand kits and an ABI Prism 7300 sequence detector (both from Applied Biosystems), according to the manufacturer's instructions. The list of TaqMan probes is shown in Supplemental Table 1.

Insulin secretion and insulin contents. EndoC- $\beta \mathrm{H} 1$ cells were seeded onto Matrigel- and fibronectin-coated 24-well plates at $4 \times 10^{5}$ cells/well. 
A

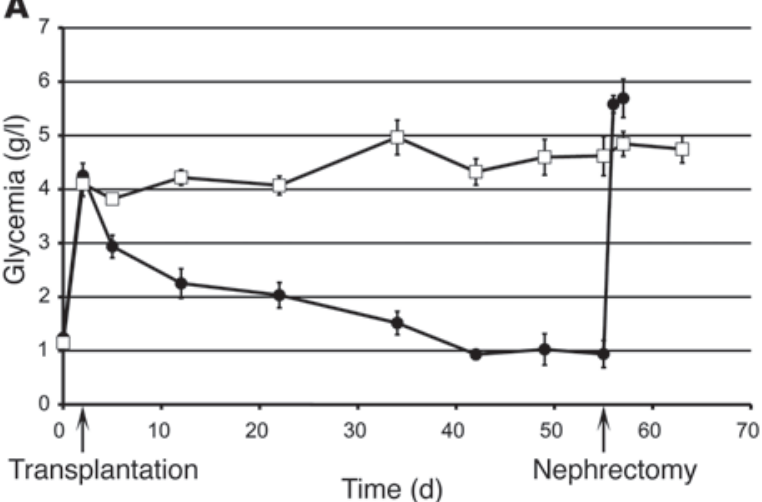

B

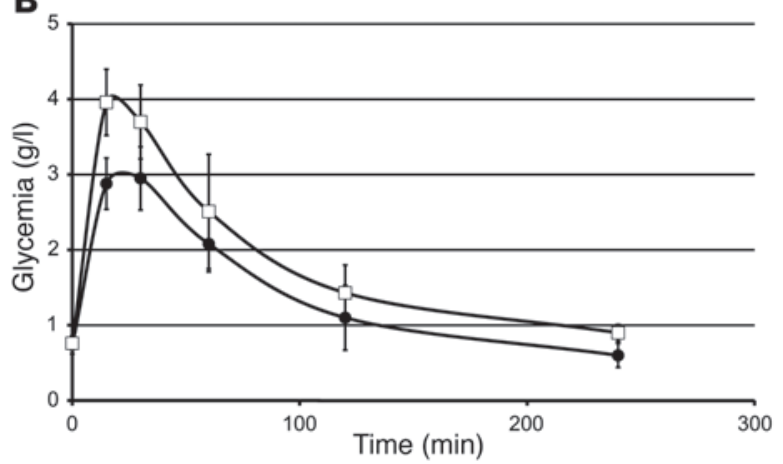

C

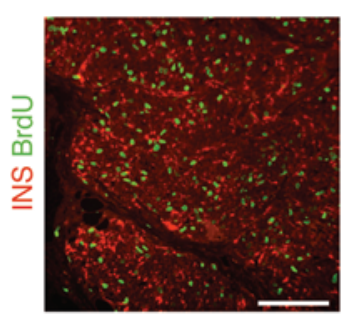

D

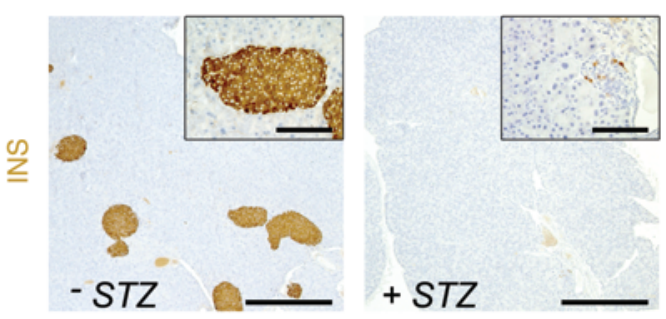

Figure 7

Normoglycemia is restored after an EndoC- $\beta \mathrm{H} 1$ cell transplant into diabetic SCID mice. (A) DM was chemically induced in 12 SCID mice by an intraperitoneal injection of STZ. 2 days later, $2 \times 10^{6}$ EndoC- $\beta$ H1 cells were transplanted under the kidney capsule in 6 of the 12 DM mice. The transplanted cells were removed by unilateral nephrectomy 55 days later. Each point is the mean \pm SEM of blood glucose levels that were measured at different time points in the transplanted (circles) or nontransplanted (squares) SCID mice. (B) An intraperitoneal glucose tolerance test was performed on the STZ-induced DM SCID mice with the EndoC- $\beta \mathrm{H} 1$ cell graft, 35 days after the cell transplant. Proper regulation of blood glucose levels was observed in the cell-transplanted DM SCID mice (circles) when compared with those of the control nonDM SCID mice (squares). Each point in the graph is the mean \pm SEM from 4 mice in each group. (C) Insulin (red) and Ki67 (green) costaining in the cell transplant after its removal by unilateral nephrectomy. (D) The pancreas of the DM mice (+STZ) with the EndoC- $\beta \mathrm{H} 1 \mathrm{cell}$ graft is almost devoid of insulin-positive cells (brown), whereas non-DM mice (-STZ) present a large number of insulin-positive islets. Scale bars: $25 \mu \mathrm{m}(\mathbf{C}) ; 500 \mu \mathrm{m}(100 \mu \mathrm{m}$ in the inset) (D).

Four days later, cells were incubated overnight in culture medium that contained $2.8 \mathrm{mM}$ glucose, and then in HEPES-buffered Krebs-Ringer Buffer (KRB) $\left(116 \mathrm{mmol} / 1 \mathrm{NaCl}, 5.06 \mathrm{mmol} / 1 \mathrm{KCl}, 1.007 \mathrm{mmol} / \mathrm{l} \mathrm{CaCl}_{2}\right.$, $1.01 \mathrm{mmol} / \mathrm{l} \mathrm{MgCl}$, $1.19 \mathrm{mmol} / 1 \mathrm{KH}_{2} \mathrm{PO}_{4}, 23.96 \mathrm{mmol} / 1 \mathrm{NaHCO}_{3}$, $10 \mathrm{mmol} / 1$ HEPES, $\mathrm{pH} 7.4$, and $0.2 \% \mathrm{BSA}$ solution that contained $0.5 \mathrm{mM}$ glucose) for 60 minutes. At the end of this incubation, stimulated insulin secretion of the cells was measured by static incubation in KRB that contained varying glucose concentrations for 60 minutes. Leucine (Sigma-Aldrich) was tested at $2.8 \mathrm{mM}$ glucose, whereas exendin-4 (Polypeptide Laboratory), glibenclamide (MP-Biomedical), IBMX (Sigma-Aldrich), and diazoxide (Sigma-Aldrich) were all tested at 11 $\mathrm{mM}$ glucose. For the back-to-baseline experiment, insulin secretion was first stimulated for 60 minutes with $11 \mathrm{mM}$ glucose in the presence or absence of IBMX. This medium was then replaced with KRB that contained $2.8 \mathrm{mM}$ glucose, and the cells were then incubated for 60 minutes. For insulin content measurement, cells were lysed in ice-cold acid ethanol $(75 \%$ ethanol, $1.5 \% \mathrm{HCl})$ and incubated overnight in this extracting solution at $4{ }^{\circ} \mathrm{C}$. Lysate was next sonicated and centrifuged for 2 minutes at $20,000 \mathrm{~g}$. Samples were kept frozen at $20^{\circ} \mathrm{C}$ before use. Insulin secretion and intracellular content of the EndoC- $\beta \mathrm{H} 1$ cells were measured by ELISA according to manufacturer's instructions using the
Human Insulin Kit (Mercodia), which was chosen because the insulin in the kit does not cross-react with proinsulin.

EndoC- $\beta H 1$ cells transplantation in DM SCID mice. In order to determine the ability of the EndoC- $\beta \mathrm{H} 1$ cells to regulate the glycemia of DM mice, DM was induced in 12 SCID mice by intraperitoneal injection of STZ $(180 \mathrm{mg} / \mathrm{kg}$ body weight; Sigma-Aldrich) in a citrate buffer. The blood glucose levels were measured in tail vein blood using a portable glucose meter (GlucoMen; A. Menarini Diagnostics). Two days after the STZ injection, $2 \times 10^{6}$ EndoC- $\beta$ H 1 cells were grafted into each DM SCID mouse using the following procedure: briefly, cultured EndoC- $\beta \mathrm{H} 1$ cells were harvested and centrifuged for 10 minutes at $4^{\circ} \mathrm{C}$. The cell pellet was resuspended in $12 \mu \mathrm{l}$ of ice-cold Matrigel (BD Bioscience) and then transferred to a silicone cylinder in order to enable the cells to polymerize at $37^{\circ} \mathrm{C}$. The cylinder was then transplanted under the kidney capsule of an STZ-induced DM mouse. In order to confirm the contribution of the EndoC- $\beta \mathrm{H} 1$ cell graft to the normalization of blood glucose levels, the grafts were removed by unilateral nephrectomy at day 55 .

Thirty-five days later, an intraperitoneal glucose tolerance test was done in the DM SCID mice with the EndoC- $\beta \mathrm{H} 1$ cell graft, and the results were compared with those of control non-DM SCID mice. For this purpose, a solution of $2 \mathrm{mg}$ glucose/g body weight in $0.9 \% \mathrm{NaCl}$ was injected intraperitoneally 
into overnight-fasted mice. Blood glucose levels in tail vein blood were measured at $0,15,30,60,120$, and 240 minutes after the injection.

\section{Acknowledgments}

The authors would like to thank the Beta Cell Biology Consortium for providing the antibodies against human $\mathrm{C}$-peptide and rabbit NKX6-1. They would also like to thank Arieh Bozon for editing the manuscript. We express our gratitude to the "Unite d'Orthogenie from Hopital Louis Mourrier Paris" and "Hopital intercommunal de Saint Germain" for the invaluable help in collecting human tissues. This research project results from collaboration among Endocells, INSERM, and CNRS. It was partly supported by funding from the 7 th Framework Program of the European Union

1. Beattie GM, et al. Sustained proliferation of PDX-1+ cells derived from human islets. Diabetes. 1999;48(5):1013-1019.

2. Russ HA, Bar Y, Ravassard P, Efrat S. In vitro proliferation of cells derived from adult human beta-cells revealed by cell-lineage tracing. Diabetes. 2008;57(6):1575-1583.

3. Kroon E, et al. Pancreatic endoderm derived from human embryonic stem cells generates glucoseresponsive insulin-secreting cells in vivo. Nat Biotechnol. 2008;26(4):443-452.

4. Asfari M, Janjic D, Meda P, Li G, Halban P, Wolheim K. Establishement of 2-mercaptoethanoldependent differentiated insulin secreting cell lines. Endocrinology. 1992;130(1):167-178.

5. Gazdar A, et al. Continuous, clonal, insulin- and somatostatin-secreting cell lines established from a transplantable rat islet cell tumor. Proc Natl Acad Sci US A. 1980;77(6):3519-3523.

6 . Santerre R, et al. Insulin synthesis in a clonal cell line of simian virus 40-transformed hamster pancreatic beta cells. Proc Natl Acad Sci U S A. 1981;78(7):4339-4342.

7. Efrat $S$, et al. $\beta$ cell lines derived from transgenic mice expressing a hybrid insulin gene-oncogene. Proc Natl Acad Sci U S A. 1988;85(23):9037-9041.

8. Miyazaki J, et al. Establishment of a pancreatic beta cell line that retains glucose- inducible insulin secretion: special reference to expression of glucose transporter isoforms. Endocrinology. 1990; 127(1):126-132.

9. Hohmeier HE, Newgard CB. Cell lines derived from pancreatic islets. Mol Cell Endocrinol. 2004; 228(1-2):121-128.

10. de la Tour D, et al. Beta-cell differentiation from a human pancreatic cell line in vitro and in vivo. Mol Endocrinol. 2001;15(3):476-483.

11. Demeterco C, Itkin-Ansari P, Tyrberg B, Ford LP, Jarvis RA, Levine F. c-Myc controls proliferation versus differentiation in human pancreatic endocrine cells. J Clin Endocrinol Metab. 2002;87(7):3475-3485.

12. Gueli N, Toto G, Palmieri G, Carmenini G, Delfino A, Ferrini U. In vitro growth of a cell line originated from a human insulinoma. J Exp Clin Cancer Res. 1987;4:281-285.

13. Levine F, et al. Development of a cell line from human fetal pancreas. Transplant Proc. 1995; 27(6):3410.

14. Narushima M, et al. A human beta-cell line for transplantation therapy to control type 1 diabetes. Nat Biotechnol. 2005;23(10):1274-1282.

15. Hohmeier HE, Newgard CB. Islets for all? Nat Biotechnol. 2005;23(10):1231-1232.

16. Castaing M, Duvillie B, Quemeneur E, Basmaciogullari A, Scharfmann R. Ex vivo analysis of acinar and endocrine cell development in the human under grant agreements no. 241883 and from the Innovative Medicine Initiative under grant agreement no. 115005.

Received for publication April 12, 2011, and accepted in revised form June 15, 2011.

Address correspondence to: Philippe Ravassard, ICM, Biotechnology and Biotherapy, CHU Pitié Salpêtrière 47 Bd. de l'Hôpital 75013 Paris, France. Phone: 33.1.57274575; Fax: 33.1.42.17.53.33; E-mail: philippe.ravassard@upmc.fr. Or to: Raphael Scharfmann, INSERM U845, Research Center Growth and Signalling, Faculty Necker, 156 rue de Vaugirard, 75015 Paris, France. Phone: 33.1.40615565; Fax: 33.1.43.06.04.43; E-mail: raphael.scharfmann@inserm.fr. embryonic pancreas. Dev Dyn. 2005;234(2):339-345.

17. Castaing M, Peault B, Basmaciogullari A, Casal I, Czernichow P, Scharfmann R. Blood glucose normalization upon transplantation of human embryonic pancreas into beta-cell-deficient SCID mice. Diabetologia. 2001;44(11):2066-2076.

18. Scharfmann R, Xiao X, Heimberg H, Mallet J, Ravassard P. Beta cells within single human islets originate from multiple progenitors. PLoS One. 2008;3(10):e3559.

19. Ling Z, Pipeleers D. Prolonged exposure of human beta cells to elevated glucose levels results in sustained cellular activation leading to a loss of glucose regulation. J Clin Invest. 1996;98(12):2805-2812.

20. Melloul D, Marshak S, Cerasi E. Regulation of insulin gene transcription. Diabetologia. 2002;45(3):309-326.

21. Schuit FC. Is GLUT2 required for glucose sensing? Diabetologia. 1997;40(1):104-111.

22. Thorens B, Sarkar H, Kaback H, Lodish H. Cloning and functional expression in bacteria of a novel glucose transporter present in liver, intestine, kidney, and $\beta$-pancreatic islet cells. Cell. 1988;55(2):281-290.

23. DeVos A, et al. Human and rat beta cells differ in glucose transporter but not in glucokinase gene expression. J Clin Invest. 1995;96(5):2489-2495.

24. Ferrer J, Benito C, Gomis R. Pancreatic islet GLUT2 glucose transporter mRNA and protein expression in humans with and without NIDDM. Diabetes. 1995;44(12):1369-1374

25. Eizirik D, Pipeleers D, Ling Z, Welsh N, Hellerstrom C, Andersson A. Major species differences between humans and rodents in the susceptibility to pancreatic $\beta$-cell injury. Proc Natl Acad Sci U S A. 1994;91(20):9253-9256.

26. Eizirik DL, Welsh N, Hellerstrom C. Predominance of stimulatory effects of interleukin-1 beta on isolated human pancreatic islets. J Clin Endocrinol Metab. 1993;76(2):399-403.

27. Fiaschi-Taesch NM, et al. Induction of human betacell proliferation and engraftment using a single G1/S regulatory molecule, cdk6. Diabetes. 2010; 59(8):1926-1936.

28. Miller DG, Adam MA, Miller AD. Gene transfer by retrovirus vectors occurs only in cells that are actively replicating at the time of infection. Mol Cell Biol. 1990;10(8):4239-4242.

29. Parnaud G, et al. Proliferation of sorted human and rat beta cells. Diabetologia. 2008;51(1):91-100.

30. Friedlander SYG, et al. Context-Dependent Transformation of Adult Pancreatic Cells by Oncogenic K-Ras. Cancer Cell. 2009;16(5):379-389.

31. Itkin-Ansari P, et al. PDX-1 and cell-cell contact act in synergy to promote delta-cell development in a human pancreatic endocrine precursor cell line. Mol Endocrinol. 2000;14(6):814-822.

32. Wang $\mathrm{S}$, et al. Isolation and characterization of a cell line from the epithelial cells of the human fetal pancreas. Cell Transplant. 1997;6(1):59-67.

33. Polak M, Bouchareb-Banaei L, Scharfmann R, Czernichow P. Early pattern of differentiation in the human pancreas. Diabetes. 2000;49(2):225-232.

34. Ravassard P, et al. A new strategy to generate functional insulin-producing cell lines by somatic gene transfer into pancreatic progenitors. PLoS One. 2009; 4(3):e4731.

35. Haataja L, Gurlo T, Huang CJ, Butler PC. Islet amyloid in type 2 diabetes, and the toxic oligomer hypothesis. Endocr Rev. 2008;29(3):303-316.

36. Westermark GT, Westermark P, Nordin A, Tornelius E, Andersson A. Formation of amyloid in human pancreatic islets transplanted to the liver and spleen of nude mice. Ups J Med Sci. 2003; 108(3):193-203.

37. Westermark GT, Westermark P, Berne C, Korsgren O. Widespread amyloid deposition in transplanted human pancreatic islets. N Engl J Med. 2008; 359(9):977-979.

38. Brandhorst H, Brandhorst D, Brendel MD, Hering BJ, Bretzel RG. Assessment of intracellular insulin content during all steps of human islet isolation procedure. Cell Transplant. 1998;7(5):489-495.

39. Lukowiak B, et al. Identification and purification of functional human beta-cells by a new specific zinc-fluorescent probe. J Histochem Cytochem. 2001;49(4):519-528.

40. Huypens P, Ling Z, Pipeleers D, Schuit F. Glucagon receptors on human islet cells contribute to glucose competence of insulin release. Diabetologia. 2000;43(8):1012-1019.

41. Castaing M, Guerci A, Mallet J, Czernichow P, Ravassard P, Scharfmann R. Efficient restricted gene expression in beta cells by lentivirus-mediated gene transfer into pancreatic stem/progenitor cells. Diabetologia. 2005;48(4):709-719.

42. Zufferey R, Nagy D, Mandel RJ, Naldini L, Trono D. Multiply attenuated lentiviral vector achieves efficient gene delivery in vivo. Nat Biotechnol. 1997; 15(9):871-875.

43. Ricordi C, Lacy PE, Finke EH, Olack BJ, Scharp DW. Automated method for isolation of human pancreatic islets. Diabetes. 1988;37(4):413-420.

44. Attali M, et al. Control of beta-cell differentiation by the pancreatic mesenchyme. Diabetes. 2007; 56(5):1248-1258.

45. Duvillie B, Attali M, Bounacer A, Ravassard P, Basmaciogullari A, Scharfmann R. The mesenchyme controls the timing of pancreatic $\{$ beta\}-cell differentiation. Diabetes. 2006;55(3):582-589.

46. Haumaitre C, Lenoir O, Scharfmann R. Histone deacetylase inhibitors modify pancreatic cell fate determination and amplify endocrine progenitors. Mol Cell Biol. 2008;28(20):6373-6383. 